\title{
Teaching Culture and Identifying Language Interference Errors through Films
}

\author{
Arman Argynbayev ${ }^{1}$, Dana Kabylbekova ${ }^{1}$ \& Yusuf Yaylaci ${ }^{1}$ \\ ${ }^{1}$ Faculty of Philology and Educational Sciences, Suleyman Demirel University, Kaskelen, Kazakhstan \\ Correspondence: Arman Argynbayev, Faculty of Philology and Educational Sciences, Suleyman Demirel \\ University, 1/1 Abylaikhan Street, Kaskelen city, Almaty province, 040900, Kazakhstan. Tel: \\ 011-7-701-321-1195. E-mail: argynbay.arman@sdu.edu.kz
}

$\begin{array}{lc}\text { Received: June 1, } 2014 & \text { Accepted: July 3, } 2014 \quad \text { Online Published: August 14, } 2014 \\ \text { doi:10.5539/elt.v7n9p49 } & \text { URL: http://dx.doi.org/10.5539/elt.v7n9p49 }\end{array}$

\begin{abstract}
This study reflects intermediate level learners' opinion about employing films in the EFL classroom for teaching culture and avoiding negative language transfer. A total of 63 participants, aged 21-23, took part in the experiment in the Faculty of Philology at Suleyman Demirel University in Almaty, Kazakhstan. During the experiment the subjects were demonstrated six extracts with culture laden scenes in a time range of 1-3 minutes. Participants had to detect peculiarities of American and Japanese cultures and compare them with Kazakh traditions. In the second part of the experiment, the subjects had to dub the film clips from Russian into English and compare their work with the original sequence. The study showed that the participants enjoyed both activities, and were ready to do them on a regular basis. Students also claim that Japanese and Kazakh cultures have certain similarities, yet there are significant differences too. The learners also assert that Kazakhs have been affected by globalization. As a result, Kazakhs share beliefs and opinions of American culture in some aspects. The most frequent mistakes in dubbing among the learners were omitting articles, incorrect word order in direct and indirect questions, incorrect use of present perfect and past simple tenses, and word-for-word translation. This work adds to the field of culture, language transfer and using films in the EFL classroom.
\end{abstract}

Keywords: culture, dubbing, film, language transfer, language interference

\section{Introduction}

With the development of technology and emerging of digital video, films have gained popularity in the EFL classroom for their practicality and authenticity. As Swaffar and Vlatten (1997) state films enable learners to observe real-life communication when native speakers interact in the authentic settings. Moreover, movies provide visual clues in addition to audio and written inputs, which support comprehension and production in L2 (Hanley et al., 1995). As a result, learners get more interested and motivated to work with films rather than being limited to textbooks in the educational process. Another undeniable advantage of films is the fact that they are invaluable source for teaching culture in the EFL classroom. Herron et al. $(1995$, p. 775$)$ asserts that video is valued for contextualizing language and illustrates the foreign culture more efficiently than other teaching aids. Furthermore, video materials are more effective than audio tracks as they reduce ambiguity due to the visual support. As a result, all these factors motivate students to learn the foreign language.

With this in mind, the purpose of this study is to examine how effectively films can be applied with Kazakhstani learners for teaching a foreign culture. Another goal of the study is to elicit frequent negative transfer errors in the participants' writing through dubbing activity.

\section{Literature Review}

Culture has been defined in many different ways, one of which is the shared knowledge and schemes created by a group of people for perceiving, interpreting, expressing, and responding to social realities around them (Lederach, 1995, p. 9). Another definition is a system of shared beliefs, values, customs, behaviors and artifacts that members of a society use to interact with their world and one another (Klingner et al., 2005).

Bennett (1993) states that learning a language separately from culture is a straight way to become a fluent fool. A fluent fool is referred to as someone who fluently speaks a foreign language, but does not perceive the social and philosophical background of that language. In a similar way, Bada (2000) stresses on the importance of 
teaching culture in foreign language classrooms. He claims that if language learners are not taught cultural elements of the target language, they may encounter difficulties in conveying a message to the speakers of the target society. Moreover, Bada (2000) suggests that learning a language in the cultural context may facilitate understanding of how native speakers use the language under certain circumstances. Therefore, language cannot be dealt separately from culture and teaching a foreign language should include teaching culture of the target society. Rivers (1981) asserts that there should be at least seven goals in culture instruction. In this study, however, we will focus on three aims only - making learners aware of the way people act; how people typically act under different circumstances; and being critical about the target language culture.

Another aspect that we investigate in this research is language transfer. According to Weinreich (1979), language transfer, also known as language interference, is a deviation from norms of both languages in the speech of bilinguals as a result of language contact. A more detailed definition is given by Odlin (1993, p. 27) where language transfer is defined as "the influence resulting from similarities and differences between the target language and any other language that has been previously (and perhaps imperfectly) acquired".

This concept is classified by Krashen (1981) into two types: positive and negative transfers, where positive transfer occurs when literacy in native language helps a student to learn a foreign language by transferring concepts from the mother tongue and applying them to the foreign one. Similarly, Cummins (1982) proposed the "Iceberg Theory". In his theory, Cummins (1982) states that proficiency in the first language can be beneficial for second language acquisition. The theory claims that students can learn a second language easier because they have already learned language devices and concepts in their first language. Students don't have to re-learn new concepts, they are only required to re-label the terms in the second language. Cummins (1981) believes that concepts and skills are typically developed in the native language before they are transferred to the second. For this reason it is crucial for students to continue to obtain input and practice in their native language.

In his work Krashen (1981) also mentions "negative transference" as one of the frequent sources of errors. Students are believed to overtly rely on word form and structure resemblances in both languages, which results in usage of false cognates and incorrect word-for-word translation. For example, Russian-speaking learners may incorrectly use the adjective "accurate", assuming that it means "neat".

In his research Parera (2004) concludes that negative transfer occurs as a result of insufficient mastery of L2 and classifies it into conscious and unconscious transfer. The scientist classifies four types of mistakes in negative language transfer: omission, addition, malformation and disordering. In a similar way, Odlin (1993) classifies negative transfer into four types: underproduction, overproduction, production errors and misinterpretation.

Underproduction errors occur when language learners omit some elements in L2 under the influence of L1. For instance, Where he live? (Where does he live?) According to Odlin (1993) underproduction appears when a speaker avoids using difficult structures in L2 because they are different from L1. Therefore, the learner tends to underproduce certain structures in L2.

Overproduction errors occur when a learner adds some elements from L1 to L2 under the influence of mother tongue. For example, Nobody doesn't know (Nobody knows). Kazakh and Russian-speaking learners have a tendency to commit such errors as double negation is possible in both Kazakh and Russian. Odlin (1993), however, defines overproduction as the overuse of structures the student is confident with as a result of poor mastery of difficult structures in the target language, i.e. underproduction.

Production errors are classified into two types: substitutions and calques. Substitutions are defined as the use of L1 forms in L2, for example, privat instead of private, while calques are the errors caused by the L1 structure. For instance, Kazakh-speaking learners can transfer word order from their native language and say I English study instead of I study English.

Misinterpretation is referred to some structures in L1 that might influence comphrehension in the target language. As a result, learners may misinterperet the message the native speaker wanted to convey.

\section{Method}

There were two main purposes in this study. The first goal was to examine the effectiveness of using films in teaching culture. The second aim was to elicit the most frequent language interference errors in students' writing through dubbing activity. The study addressed the following questions:

1) How successfully can films be applied in teaching culture in Kazakhstani environment?

2) Can EFL students perceive culture differences in films?

3) What are the most frequent types of negative language transfer in students' writing? 
The participants were 63 bilingual and multilingual university students at B1 level in the age range of 21-23. No distinction was made between Kazakh-speaking and Russian-speaking learners as they all came from the same multicultural background. Moreover, the researchers were interested in studying students' opinions about foreign cultures as a whole. The criterion for selection of population was a sufficient fluency in English as the experiment included the task in which the participants had to dub the film clips from Russian into English. The research site was the Faculty of Philology at Suleyman Demirel University, Kazakhstan.

\subsection{Procedures}

Six episodes with culture laden scenes were selected from the Hollywood film "The Last Samurai". The clips were in the time range of 1-3 minutes and were labeled according to the scene for better comprehension while watching: Algren meets Graham, Katsumoto meets Algren, Katsumoto and Algren talk about general Castor, Taka asks her brother Katsumoto, Algren describes Japanese culture, and Algren apologizes to Taka. During a week three groups of students watched all six episodes. However, it was decided that each group would dub two different film extracts only so as not to make the learners bored or tired with the same activity. It was believed that by doing so the purity of the experiment would not be affected by tiredness of the participants.

At each session the subjects in each group had to complete two tasks:

1) Detect as many culture peculiarities as possible portrayed in the film, and write reflections comparing American, Japanese and Kazakh cultures.

2) Dub two film clips from Russian into English, subsequently checking for mistakes with the original sequence in English.

Finally, the students were given a questionnaire to complete and participated in a whole class discussion, in which they shared their findings about Japanese and American cultures, compared them with Kazakh traditions and behavior, and received feedback from the instructor and their peers.

\section{Results and Discussion}

As it was mentioned above, along with their reflection the participants had to answer the questionnaire and give reasons why they thought so. The results of the questionnaire are shown in Table 1 below.

Table 1. Opinion of the students about the application of films in the EFL classroom

\begin{tabular}{lllll}
\hline Questions & Yes & No & Somewhat & Don't know \\
\hline 1. Is it effective to use films in teaching a foreign culture? & $91 \%$ & $2 \%$ & $7 \%$ & \\
2. $\begin{array}{l}\text { Does the film portray Japanese and American cultures in a } \\
\text { reliable and relevant way? }\end{array}$ & $57 \%$ & $10 \%$ & $25 \%$ & $8 \%$ \\
3. Did you experience culture shock when watching the film? & $9 \%$ & $91 \%$ & & \\
4. Did you like the dubbing activity? & $96 \%$ & $4 \%$ & & $2 \%$ \\
5. Was your dubbing successful? & $28 \%$ & $17 \%$ & $53 \%$ & \\
6. $\begin{array}{l}\text { Do you think that dubbing can decrease the number of } \\
\text { mistakes in the target language? }\end{array}$ & $80 \%$ & $2 \%$ & $18 \%$ & \\
\hline
\end{tabular}

As we can see from Table 1 above, the vast majority of students liked watching and dubbing the film clips. Particular answers that deserve attention were:

“We need a visual stimulus and films are the best way to get us interested. Besides, you don't have to read long chapters in books, or travel abroad, so it saves time, effort and money."

"It is entertaining and illustrative at the same time."

"Through films we can learn implicit peculiarities that cannot be noticed in traditional lessons."

"We can compare many cultures simultaneously and get background knowledge of a particular culture for future ICC situations."

"After watching this movie it occurred to me that we have different traditions and ways of showing our emotions."

"Movies are shot in authentic circumstances that portray genuine traditions and situational language. This is 
why they can deliver culture details such as gestures, clothes, jokes and feelings."

However, students also noted that:

"Film is an effective way to teach intercultural competence, provided the teacher is aware of the culture himself. If some aspects are shown and are not explained, it might lead to misunderstanding. Moreover, the teacher should be equipped with appropriate materials to help his students destroy ambiguity and prejudice barriers between cultures."

"Teachers should choose movies with caution so as not to misinform the students, as many films are culturally biased and inaccurate."

"This is an American way of seeing it. Maybe Japanese people won't agree with the facts that this film shows."

"People watch films only for entertainment and don't pay attention to culture issues."

"All films choose the brightest representative moments, situations and characters and even add colour to them. Therefore, it can be said that films are valuable in artistic perspective but not in scientific or historical."

"Film directors are interested in earning money, so they can show anything that can attract a customer."

"To be able to learn the culture properly we need to watch more aspects of life such as the way they receive education, their relationship, economics, and politics."

The question if the participants had experienced culture shock was responded negatively because the subjects had already been familiar with American and Japanese cultures. The question if the students had liked dubbing activity was welcomed warmly. The students stated that there was natural and authentic communication in the film and they liked that. Some learners noticed that they still made mistakes in word order, especially in question form. Other students said that they had learnt new words, such as "temple", "worrier", "accurately", and many others. A few participants asserted that some parts of their dubbing matched $100 \%$ with the original script which pleased them a lot. In a similar way, the last question was responded positively. The students stated that if they dubbed film clips on a regular basis, they would definitely improve the target language and decrease the number of mistakes in pronunciation, word order and sentence structure.

\subsection{Similarities and Differences in American and Kazakh Cultures}

The participants noticed that greeting among men are very similar in American and Kazakh cultures. Men shake hands and can even hug each other, if they are close friends or relatives whom they have not seen for a long time. Nodding your head when greeting without shaking hands is also acceptable in both cultures, though nodding a head might be a bit lower in Kazakh culture as a token of respect.

Another similarity that the students noted was the fact that Kazakhs and Americans, unlike Japanese generals, think that every life of a soldier is precious; thereofore, there is no point in needlessly endangering lives of troopers, while Japanese armed forces, especially samurais, are ready to die in hundreds in order to follow irrational orders of their generals.

Like in every nation there are people with high moral values and immoral ones. This seems to be a universal truth. Americans and Kazakhs are similar in this respect. The participants noticed that Captain Algren was full of remorse for what he did with Red Indians in punitive raids while his superior officer Colonel Bagley was not. Colonel Bagley said that he just followed orders and that his conscious was clear. In contrast, Captain Algren suffered from nightmares as he saw faces of Indian children and women that he killed.

The first difference between American and Kazakh cultures, that the learners noticed, was the fact that Americans do not take off their shoes when entering a house. This kind of behavior is absolutly shocking for Kazakhs, who never do so. Taking your shoes off is a must, especially when visiting somebody as a guest.

The questionnaire also showed that Americans are believed to be prejudiced against Asian countries. When Captain Algren said to Colonel Baglley that he needed a bath, the colonel imagined how terribly Captain Algren felt after living with samurai savages. However, it was in Japanese captivity where the captain learnt to bath more often and to take off his boots before entering the house. The participants believe that they, unlike Americans, are not very prejudiced against Asian countries.

A very interesting finding was made by a female participant who stated:

Unlike Kazakhs, American men love spending a lot of time with their children. From the film we have learnt that American men play jokes with kids and play games with them, while traditional Kazakh men do not do so. It doesn't mean that Kazakh men do not love their children. They really do, they just don't spend much time with their kids. They believe that it is women's duty to bring up children. Nowadays, however, a lot of young fathers 
are changing their opinion about fatherhood. They try to spend more time with their kids.

The last thing the students noticed was the fact that Americans seem to have very strong principles. For example, Captain Algren refused to send his untrained Japanese troops to battle against skillful samurais in spite of the fact that he was aked to do so by the Emperor's council Mr. Omura. In Kazakhstan it is almost impossible to disagree with or disobey your employer directly as it was done by the captain.

\subsection{Similarities and Differences in Japanese and Kazakh Cultures}

From written reflections of students it becomes clear that majority of learners believe that Japanese and Kazakh cultures are similar in many ways. For instance, the participants note that men are more dominant in both cultures because they are the head of the family. Moreover, Japanese men like Kazakh men usually do not help their wives about the housework. It is believed to be women's duty while men have to do the work outside the house, such as repairing the fence, bulding a barn, etc.

The Japanese are believed to be very polite and save people's faces in uneasy and embarrassing situations, just like Kazakhs, who are ready to tell white lies in order to avoid hurting feelings of their interlocutors. Some students also noted that Japanese and Kazakh people do believe in fate and can forgive people who are responsible for the death of their family member, because it was in their relative's destiny. For example, there were many incidents in Kazakhstan when Kazakh patients died because of doctors' fatal mistakes, but the relatives of the deceased did not sue the doctors, as they believed that it was in the destiny of the deceased relative.

Another interesting issue which was mentioned is the way the Japanese keep their conversations. A few students expressed their astonishment at Katsumoto's patience and politeness towards his captive enemy, Captain Algren, who behaved impolitely and deserved to be punished. Students were also surprised to learn that it is extremely rude in Japanese culture not to introduce yourself even among enemies. In addition, despite the fact that Japanese people like conversing, they keep them short and don't talk much. Old Kazakh and Japanese traditions are also believed to be similar in terms of conveying a message to their interlocutors. Kazakhs used to tell their mind implicitly, and were extremely polite to their guests no matter how they behaved. Hospitality among Kazakhs is believed to have been preserved till today. The way the Japanese used to dinner with a family is also similar to Kazakh culture. A low round dining table called 'dastarkhan' is still popular in Kazakh villages and in the southern regions of the country. A local Korean student's response and reflections deserve a special attention. He noted that he liked the activities very much and added:

"I am Korean and Japanese culture is very close to me because I was brought up in a similar way. Honour is very important to us, as well as hospitality. When guests come, host and all his family members have to stand up no matter what they are doing and greet their guests. Guests mustn't take into host's house evil or bad thoughts and dirty things. That's why guests must take off their boots and coats before entering the living room."

A few students mentioned that they were shocked by Japanese people's perception of death and practice of hara-kiri among samurais. As they stated life is precious and it is not worth committing suicide for any reason. Mistakes can be amended or compensated.

The last thing that participants noticed about Japanese people was their perfectionist and workaholic nature which is not very common in Kazakh society.

Despite the fact that Japanese and American culture peculiarities were competently portrayed in the film, some students noted that the movie depicts old times, $19^{\text {th }}$-century Japan, and nowadays both Japanese and Kazakh way of life is influenced by globalization and Western culture. For example, an exchange student from Turkey stated that Kazakh traditions are in the middle of Western and Eastern cultures. Kazakhs also have their own national and Islamic customs and that make them Kazakh.

\subsection{Language Interference Errors}

As it was mentioned in methodology the participants had to dub the film clips from Russian into English, consequently checking their work with the original script. The students were not allowed to make any changes to their dubbing when watching the original sequences. They were only permitted to highlight their mistakes and make notes with a different colour pen. Participants' errors were classified according to Odlin's (1993) theory: underproduction, overproduction, production errors and misinterpretation. It could be observed that most mistakes were made in omission of articles, incorrect conjugation and word order.

\subsubsection{Underproduction of Articles}

There are no definite and indefinite articles in Kazakh and Russian. For this reason omitting articles is a frequent 
error among Kazakhstani learners.

Table 2. Omitting articles

\begin{tabular}{ll}
\hline L1 Interference & Expected L2 \\
\hline No, I was captain. & No, I was a captain. \\
I think it's good death. & I think it's a good death. \\
Read book. & Read the book. \\
He wasn't good general. & He wasn't a good general. \\
He is murderer. & He is a murderer. \\
We had lieutenant colonel. & We had a lieutenant colonel. \\
Twenty years ago it was small little town. & Twenty years ago it was a small little town. \\
\hline
\end{tabular}

\subsubsection{Production Errors: Word Order and Question Form}

As students noticed word order and question forms in English still caused some confusion in their speech and writing. This statement is proved by Table 3 below. These errors seem to stem from direct L1 translation and L1word order.

Table 3. Word order and question form

\begin{tabular}{ll}
\hline L1 Interference & Expected L2 \\
\hline Because we both are students of war. & Because we are both students of war. \\
How many worriers had Castor? & How many worriers did Castor have? \\
What need you from me? & What do you need from me? \\
Why need these conversations? & Why do we need these conversations? \\
What the hell I am doing here? & What the hell am I doing here? \\
For what? & Why? \\
\hline
\end{tabular}

\subsubsection{Production Errors: Overgeneralization}

Once students learn the rules of how to form past simple and past perfect, they seem to overgeneralize the rules and apply them to question form. Furthermore, in Kazakh and Russian verbs in questions and in affirmative sentences have the same form and tense. These factors are believed to confuse learners and push them to use inappropriate structures.

Table 4. Production errors: overgeneralization

\begin{tabular}{ll}
\hline L1 Interference & Expected L2 \\
\hline Have you ever foughted against Indians? & Have you ever fought against Indians? \\
If that will be my fate. & If that is my fate. \\
Did I kill her husband? & Did I kill her husband? \\
$\ldots$ in the country where no one doesn't tell .... & $\ldots$ in the country where no one tells ... \\
I don't know which day is it. & I don't know which day it is. \\
\hline
\end{tabular}

\subsubsection{Overproduction}

Many students tend to think in Russian when speaking English and commit errors due to this process. As it can be seen from Table 5, learners translate "будет" as "will be" instead of "will have". Another language transfer occurred in the phrase 'позволить себе' where 'себе' is a reflective pronoun. As a result, some students used 
'afford themselves to do something' instead of 'afford to do something'. The same is true with the verb 'feel'. In Russian this verb is used with a reflective pronoun when used as a state verb.

Table 5. Overproduction errors

\begin{tabular}{ll}
\hline L1 Interference & Expected L2 \\
\hline Maybe one day you will be also such a ... & Maybe one day you will also have such a ... \\
$\ldots$ many people cannot afford themselves to ... & $\ldots$ many people cannot afford to ... \\
Sometimes I feel myself like I'm living in a frame. & Sometimes I feel like I'm living in a frame. \\
\hline
\end{tabular}

\subsubsection{Production Errors: Present Perfect Tense}

There is no Present Perfect tense in Russian nor is there Past Participle. Some students cannot differentiate Past Simple from Present Perfect as in Russian they both have the same form. Examples of negative language transfer are shown in Table 6 below.

Table 6. Production errors: present perfect tense

\begin{tabular}{ll}
\hline L1 Interference & Expected L2 \\
\hline Have you been the general of your army? & Were you the general of your army? \\
I have never seen such discipline. & I have never seen such discipline. \\
Did you finish yet? & Have you finished yet? \\
\hline
\end{tabular}

\subsubsection{Vocabulary Errors}

Vocabulary errors are caused as a result of word-for-word translation from Russian into English. The study revealed that a number of participants cannot distinguish Russian polysemantic words and tend to use their first meaning in English without consulting a dictionary or taking an effort to learn its different connotations.

Table 7. Vocabulary errors

\begin{tabular}{ll}
\hline L1 Interference & Expected L2 \\
\hline Is it a low rank?-Average. & Is it a low rank?-Middle. \\
$\ldots$ red skin Indians ... & $\ldots$ red Indians ... \\
$\ldots$ to recognize my enemy... & $\ldots$ to know my enemy... \\
I was fired quickly. & I was soon fired. \\
It was an honour to cut his head. & It was an honour to cut off his head. \\
\hline
\end{tabular}

\section{Conclusion}

The present study revealed that using films in the EFL classroom can be effectively applied in teaching foreign cultures. It motivates students, keeps them interested and involved in the learning process. Participants claimed that through films they can learn implicit aspects of a foreign culture that cannot be learnt from books or other materials. However, the learners also stated that movies can be biased and unreliable. For this reason teachers should know the target culture well and select films with caution.

The research also confirmed that videos can be used for identifying and reducing negative language transfer in writing. The participants enjoyed dubbing film extracts and comparing them to the original script. The subjects mentioned that films, unlike adapted coursebooks, demonstrate natural and authentic dialogues. Moreover, videos facilitate comprehension as they have visual clues. Most frequent mistakes in students' dubbing were omitting articles, incorrect word order in direct and indirect questions, confusing perfect tenses with simple tenses and word-for-word translations. Other types of errors that were not mentioned in this paper were "subject-verb agreement", "auxiliary verb disagreement in tag-questions", "overproduction of the verb 'to be' in 
questions and negative forms". These mistakes were not discussed as they are believed to be the result of low proficiency in the target language rather than negative influence of L1 on L2 acquisition.

\section{References}

Bada, E. (2000). Culture in ELT. Cukurova University Journal of Social Sciences, 6, 100-110.

Cummins, J. (1982). Tests, achievement, and bilingual students, Focus, No. 9. Arlington, VA: National Clearinghouse for bilingual education.

Cummins, J. (1981). Educational success for Canadian minority language children: The role of mother tongue development. Canadian Journal of Italian Studies, 4, 299-315.

Hanley, J., Herron, C., \& Cole, S. P. (1995). Using video as an advance organizer to a written passage in the FLES classroom. Modern Language Journal, 79, 57-66.

Herron, C., Morris, M., Secules, T., \& Curtis, L. (1995). A comparison study of the effects of video-based versus text-based instruction in the foreign language classroom. French Review, 68, 775-795.

Krashen, S. D. (1981). Second language acquisition and second language learning. California: Pergamon Press Inc.

Klingner, J., Artiles, A. J., Kozleski, E., Harry, B., Zion, S., Tate, W., ... Duran, G. Z. (2005). Addressing the disproportionate representation of culturally and linguistically diverse students in special education through culturally responsive educational systems. Education Policy Analysis Archives, 13, 1-43.

Lederach, J. P. (1995). Preparing for peace: Conflict transformation across cultures. Syracuse, NY: Syracuse University Press.

Odlin, T. (1993). Language Transfer: Cross-linguistic Influence in Language Learning. Cambridge, CUP. http://dx.doi.org/10.1075/jpcl.8.1.13byr

Parera, J. D. (2004). Teori Semantik. Jakarta: Erlangga.

Rivers, W. M. (1981). Teaching foreign language skills. Chicago: The University of Chicago Press.

Swaffar, J., \& Vlatten, A. (1997). A sequential model for video viewing in the foreign language curriculum. Modern Language Journal, 81(1), 175-188. http://dx.doi.org/10.1111/j.1540-4781.1997.tb01173.x

Weinreich, U. (1979). Languages in Contact: Findings and Problems of Research. Berlin: De Gruyter, Mouton Press.

\section{Copyrights}

Copyright for this article is retained by the author(s), with first publication rights granted to the journal.

This is an open-access article distributed under the terms and conditions of the Creative Commons Attribution license (http://creativecommons.org/licenses/by/3.0/). 